\title{
Programas de concerto como fontes relevantes para a historiografia da música - tensões e ideologias com base em repertórios musicais na cidade de Curitiba (1945-1963)
}

Concert programs as relevant sources for the historiography of music - tensions and ideologies based on musical repertoires in the city of Curitiba (1945-1963)

Programas de concierto como fuentes relevantes para la historiografía de la música - tensiones e ideologías con base en repertorios musicales en la ciudad de Curitiba (1945-1963)

Alan Rafael de Medeiros

\section{Resumo}

O presente artigo expressa uma investigação baseada em programas de concerto como fonte primária, analisando o posicionamento estético da instituição de promoção musical Sociedade de Cultura Artística Brasílio Itiberê (Scabi) por meio do repertório disseminado em Curitiba-PR. A partir do levantamento quantitativo de obras dos compositores e suas respectivas vinculações estéticas ao longo de cada temporada artística da Scabi (1945-1963), é possível confirmar uma prática de repertório enraizada na tradição musical do século XIX com incursões na produção nacionalista. Acredita-se que tal atuação revela um movimento no sentido de oportunizar a internalização de um tipo de repertório institucionalizado, justificando o nacionalismo sem entretanto romper com o repertório canônico da tradição europeia, em momento nítido de tensões no campo da música de concerto entre o nacionalismo $\mathrm{x}$ universalismo.

Palavras-chave: Nacionalismo musical. Programas de concerto. Repertório canônico.

Doutor em História pela Universidade Federal do Paraná. Professor da Universidade Federal do Paraná, modalidade Parfor - Licenciatura em Música. E-mail: alanmaestro@ yahoo.com.br.

Recebido em 06/7/2017 - Aprovado em 28/8/2017 http://dx.doi.org/10.5335/hdtv.18n.1.7744 


\section{Introdução}

O presente trabalho objetiva fornecer um estudo de caso tendo programas de concerto enquanto fontes na análise da produção musical em um dado contexto social, historicamente constituído. A partir dessa perspectiva, busca-se compreender o posicionamento estético da Sociedade de Cultura Artística Brasílio Itiberê (Scabi), uma entidade civil sem fins lucrativos fundada e atuante em Curitiba entre 1945 e 1976, que estimulou a prática de música por meio da realização de concertos e recitais. Para além dos concertos realizados, a Scabi promoveu palestras e cursos voltados à ampliação da vivência artística na capital paranaense ao longo de 31 temporadas, contabilizando um total de 487 concertos e recitais. Pode-se dizer que a Scabi tencionou inserir Curitiba no cenário nacional de circulação dos músicos que tocavam nos principais polos brasileiros.

Fundada por indivíduos integrantes da elite intelectual, dentre os quais se destaca o administrador cultural Fernando Corrêa de Azevedo (1913-1975), presidente da instituição por 26 anos, de acordo com a ata da reunião inaugural, o surgimento dessa entidade buscava superar a estagnação artística que se estava verificando em Curitiba, em razão do "esvaziamento" das manifestações culturais na cidade entre as décadas de 1930 e 1940. Além do objetivo de constituir-se enquanto uma entidade de promoção cultural e de fruição estética musical, a instituição assumiu importante papel pragmático essencial ao período de providenciar a abertura de espaços voltados à música de concerto, bem como do seu gerenciamento, oportunizando a contratação de intérpretes, demanda estabelecida em decorrência da inexistência de organismos oficiais responsáveis pela promoção e manutenção desses espaços.

As estratégias de atuação da Scabi tanto no que diz respeito à escolha de repertório quanto em parcerias intelectuais e artísticas que buscou promover, indicam tentativas de consolidação da música de concerto em Curitiba. Sustenta-se a hipótese de que tal consolidação está associada a duas propostas específicas: uma de caráter nacionalista, que mobilizou importantes representantes da arte em torno de um debate em contraposição às tentativas de inserção de propostas estéticas experimentalistas e universalistas no país antes da década de 1960 - a vanguarda musical frente ao nacionalismo - e outra de fruição musical artística voltada à disseminação do repertório canônico tradicional europeu, respaldado pela compreensão da intelectualidade frente à heterogeneidade musical no cenário local.

Por meio da análise dos 355 programas de concerto compreendidos entre 1945-1963, ${ }^{1}$ sustenta-se a ideia de que a instituição, ao possibilitar a abertura para a reprodução musical canônica e a incursão no repertório nacionalista, iniciava a fruição dessa estética na capital. Tal realidade se deu em momento de discussão sobre a produção musical incorporada às expectativas de uma estética nacional que tinha o material folclórico como essência criativa, de outra estética que pretendia desvencilhar o processo composicional das premissas nacionalistas e criar uma 'arte pela arte', utilizando, para tanto, 
técnicas recém-discutidas e abordadas em diferentes polos europeus.

No grande bojo da história social, acredita-se que toda a abordagem historiográfica da música pode ser inserida nos domínios da história social da música. Essa perspectiva questiona possíveis elos que se poderia estabelecer entre a música e as estruturas econômicas, políticas e culturais de uma formação social, em dado momento histórico cronologicamente determinado. Do mesmo modo, deve privilegiar as conexões entre a produção artística e a sua decodificação por um público específico, além de discutir possíveis obstáculos para a concretização de um determinado projeto estético. Em síntese, deve objetivar não apenas o estudo da criação artística em relação à sociedade, mas da vida de um grupo social e da relação desse com a arte (CONTIER, 1988, p. 15).

Esse panorama oferece novos padrões quando comparados à corrente tradicional de abordagens da historiografia da música. A vertente tradicionalizante fundamentou uma narrativa que encaminhava sucessivamente a tríade autores-obras-movimentos musicais. Temos portanto: autores, tidos como gênios criadores, obras intituladas obras primas e movimentos de relevo para a história da cultura e da sociedade. O material sobre o qual os historiadores se debruçavam, sejam fontes primárias ou secundárias, comumente era resultado de memorialistas, bem como de historiadores não acadêmicos inseridos no contexto de narrativas clássicas da história da música.

Como a prática da música está circunscrita aos espaços em que ocorreu em determinado contexto histórico e o material com o qual está se relaciona - o som - é efêmero (CAMPOS, 2007, p. 71), compreende-se que sua efetividade enquanto arte formativa está relacionada às estratégias de atuação das instituições que a promoveram, seus discursos, e a consequente vinculação ideológica à qual estiveram alinhadas. Apesar de ser caracterizada como uma manifestação artística até certo ponto autônoma, como precisa ser compreendida dentro de seus próprios termos, ela não está descolada da realidade social na qual foi produzida, e além de produto da sociedade, a música é produtora de significados sociais. Nessa perspectiva, o tipo de repertório canônico promovido associará o público a determinadas correntes estéticas, relacionando a prática da música, o processo de produção e reprodução musical, e a resultante configuração de esquemas diferenciados de plateia.

2 Considerações acerca das fontes de estudo

O acervo da Scabi foi utilizado como conjunto das fontes primárias para a realização deste trabalho. De natureza distinta, o presente trabalho focou a análise com base nos programas de concerto, um documento/monumento que para além de um material alocado no passado, é produto fabricado pela sociedade de acordo com as relações de forças que detinham o poder (LE GOFF, 1996, p. 536). A abordagem de tais fontes vai ao encontro de novas concepções de documento histórico, ampliando a tradicional interpretação embasada exclusivamente na história calcada no documento oficial, que relegava a um segundo plano toda a evidência não relacionada diretamente a essa tipologia de fonte (BURKE, 1992). 
Sob a perspectiva da nova crítica documental, são repensados o alargamento do conceito de documento, sua existência ou sua ausência nos arquivos e mesmo as intenções que permearam sua existência. Esse novo enfoque está preocupado com a seletividade dos conteúdos do documento que são fruto de interesses no momento da seleção desses, e de mesmo modo, com a relação direta do historiador e sua visão de um passado histórico particular, no processo de construção do objeto por meio do documento.

A título de exemplo, outras fontes, tais como aquelas de caráter administrativo foram utilizadas no intuito de verificar o "discurso oficial" da Scabi ao longo de suas atividades artísticas. Aqui é possível visualizar informações que se relacionam aos objetivos de funcionamento da entidade, suas especificidades burocráticas, as estratégias de atuação e linhas de frente. A estrutura gerencial da Scabi demonstra em que medida as despesas básicas eram consideradas na forma como essa era gerida no momento de fechamento de contrato com músicos. Os relatórios dos anos iniciais, por exemplo, indicam as principais abordagens e os interesses da instituição no momento das parcerias estabelecidas com musicistas que se apresentaram a partir de sua intermediação. As fontes de hemeroteca utilizadas são resultado da seleção dos principais periódicos do período estudado, em especial, aqueles que contavam com espaços para artigos sobre música. São representativos nesse contexto artigos retirados do periódico O Dia, que tinha coluna especialmente dedicada à produção musical local. Além desse, o Jornal Gazeta do Povo foi outro periódico que registrou as atividades de Scabi de maneira efetiva, sendo que essa era uma publicação regular de amplo alcance social, o que indica, em certa medida, o relativo destaque obtido pela instituição no cenário local.

Contribuição significativa para a presente pesquisa está relacionada aos programas de concerto. Dada a relevância desses como fonte vinculada ao processo de disseminação musical, uma vez que constam as obras executadas, vinculadas a correntes musicais alinhadas a preceitos estético-musicais, este se constitui enquanto acessório no aprendizado da plateia e indica como determinado repertório foi constituído no cenário social. Ainda que de maneira incipiente, ela vem sendo utilizado recentemente por pesquisas musicológicas justamente por fornecer a compreensão sobre determinada associação estética no processo de disseminação musical, uma vez que oferecem repertórios e compositores disseminados. Com isso, toda uma produção musical herdada ou não da tradição canônica é oferecida em determinado espaço social, por uma determinada instituição promotora de eventos e para uma plateia específica. 


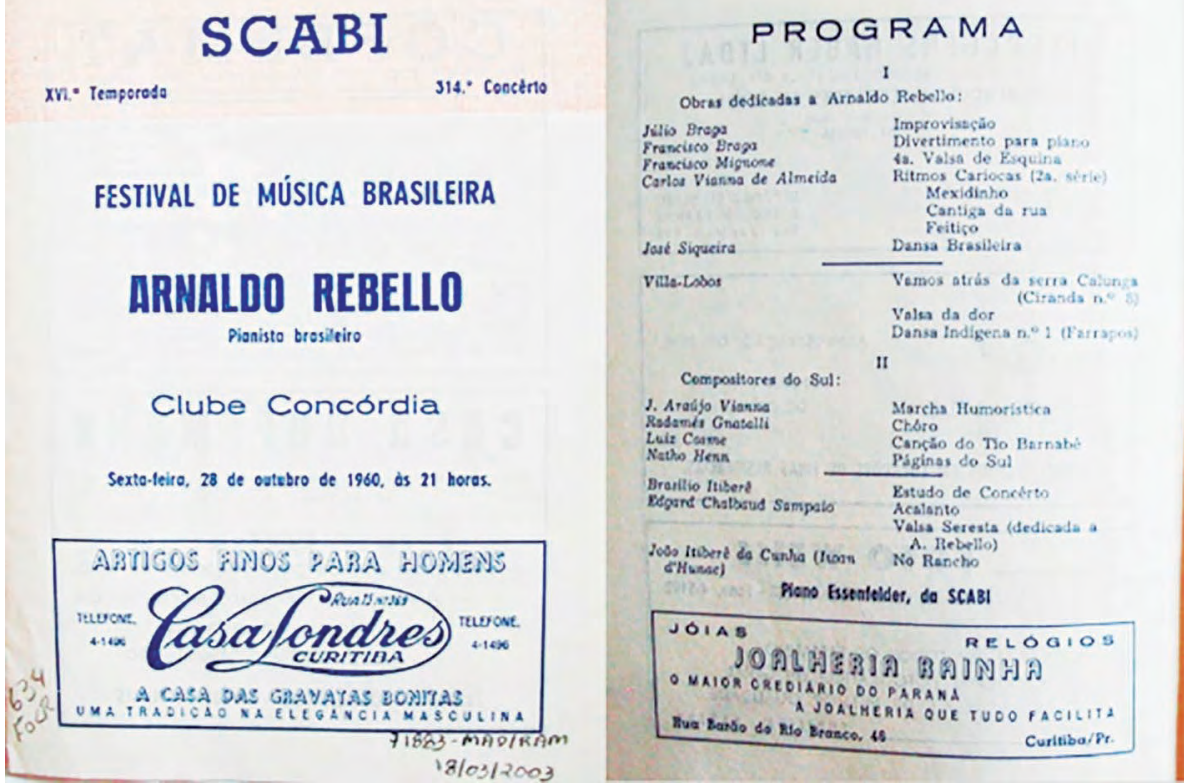

Fonte: Centro de Documentação e Pesquisa da Casa da Memória (Fundação Cultural de Curitiba). Referência de catalogação: 634 FOLR, 1960, Curitiba. SCABI, 28.10.1960².

Para a análise dos programas de concerto, após a sistematização do repertório - reflexão sobre correntes musicais às quais cada obra se vincula - as obras executadas são abordadas partindo da verificação do período de composição, o gênero específico e a respectiva vinculação estética. Essa etapa da análise é fundamental para estabelecer parâmetros basilares da veiculação das instituições a uma determinada corrente estético-musical no âmbito local, que, por sua vez, está veiculada a uma concepção mais larga dentro da estrutura artística nacional. Portanto, correlacionar adequadamente as obras às suas vinculações estéticas características se mostra relevante na delimitação das opções das instituições promotoras de eventos musicais.
Esse tipo de fonte passa a ser imprescindível na análise da tentativa de disseminação musical, uma vez que o repertório escolhido para os concertos se associa diretamente a uma determinada estrutura de pensamento estético. Analisar as relações de disseminação musical por meio dos programas de concertos realizados pela Scabi significa oferecer ferramentas para a reflexão sobre as práticas musicais em Curitiba durante o período proposto.

Os programas de concerto apresentam informações que contribuem para a visualização da trajetória e das estratégias da entidade e sua função formativa no contexto social, em especial no que diz respeito às obras, aos intérpretes e repertórios. Sua estrutura geral: a) o repertório propriamente dito; b) 
extratos de crítica favorável, que chancelavam assim a qualidade técnica do executante; c) biografia do intérprete, geralmente laudatória; d) informativos gerais, informações sobre palestras e conferências, dados sobre o compositor e a obra executada. Para além de uma apreciação musical ingênua, oferecer ao ouvinte explicações sobre a obra musical executada, dados sobre o compositor e o contexto, faz parte dos meios interpretativos como estratégia de compreensão e direcionamento estético da prática artística, que integram o escopo da iniciação cultural preconizada pelas artes de representação pública (SENNETT, 1989, p. 260).

É importante destacar que essas fontes eram incorporadas pela própria Scabi como representação de suas atividades em outras cidades. As correspondências trocadas entre o presidente da Scabi Fernando Corrêa de Azevedo com o musicólogo Francisco Curt Lange demonstram este "repertório de significados artístico-culturais":

Montevidéu, 07 de julho de 1946.

Recebi oportunamente um programa do caro amigo com uma saudação à margem. Muito obrigado. Gostaria de ter aqui uma coleção completa dos programas da Sociedade $[\mathrm{SCABI}]^{3}$.

Curitiba, 28 de julho de 1946.

Programas: Em separado, estou lhe registrando uma série dos concertos dos programas que possuo. A Cultura [SCABI] realizou até o momento 36 concertos, mas nem todos tenho o programa. O que existe estou lhe remetendo ${ }^{4}$.

Exemplos como esse indicam que os documentos da instituição musical eram representantes dessa para além do seu alcance direto. Muito mais que lembranças, representam a organização da Scabi no ce- nário curitibano, um "exemplo ilustrado" da instituição a ser utilizado por Curt Lange na apresentação da Scabi para musicistas que cogitavam realizar concertos em Curitiba. Tal intenção demonstra a importância de um programa de concerto bem elaborado, aos moldes de programas dos principais centros artísticos e, por isso, a Scabi teve o cuidado de preservá-los.

As informações existentes nas fontes que integram o acervo da Scabi contribuem para o mapeamento histórico da entidade estudada e, do mesmo modo, favorecem a compreensão de experiências no âmbito social e cultural verificadas em Curitiba. Tais fontes são analisadas de maneira a compreender os espaços de sociabilidade por ela criados e as tentativas de sua consolidação, assim como as práticas musicais e as tensões desse campo.

\section{Instituições privadas de fomento à música - ideário canônico em Curitiba por meio da Scabi}

A construção de um ideário no campo da música de concerto é efetivada na reprodução de "obras clássicas", canônicas, consideradas grandes obras compostas pelos grandes compositores do passado. Constituídas em repertórios, caracterizam-se como portadoras de valor e legitimidade, determinando o processo de funcionamento da música enquanto disciplina, indicando como os indivíduos inseridos em um dado campo aprendem, por meio da internalização dos padrões, como não transgredi-los (WEBER, 1999, p. 339). 
A canonização do repertório musical está alicerçada em um contexto de ressignificação da prática profissional do compositor ao longo do século XIX, no momento em que este viu a atividade perder sua função social objetiva (trabalho em cortes como compositor e intérprete, função de mestre de capela para produção de música para os serviços religiosos). A comercialização de concertos e do mundo operístico criou no meio musical, por parte dos compositores, um espírito reacionário cada vez maior contra a mercantilização da música, e com isso a idealização de um produto musical superior desapegado dos valores comerciais que consequentemente gravitavam como "obras musicais decadentes" passou a ser amplamente reivindicada (WEBER, 2011, p. 132).

O cânone musical, a partir dessa perspectiva, foi definido como uma força moral, espiritual e cívica, termos nos quais a tradição musical clássica europeia foi definida em seu plano basilar. Ao longo do século XIX, o cânone reivindicou para si uma aura moral e socialmente purificadora, "sacralizada" (BLANNING, 2011, p. 111), isto porque as grandes obras deveriam ser consideradas afastadas e isentas de uma relação financeira com a vida musical, no intuito de contribuir para a transcendência da sociedade, superar a cultura comercial e regenerar a vida musical (WEBER, 1999, p. 352).

A tradição das primeiras instituições privadas adotou esse padrão e, para toda realidade social influenciada pela construção idealizada dos modelos artísticos europeus, essa concepção de repertório passou a ser utilizada. No Brasil republicano da Belle Époque, as tradições importadas da Europa ditaram os costumes e estruturaram o campo da música, o modelo foi traduzido neste produto "purificador" dos séculos XVIII e XIX, em oposição às sociabilidades de repertório de música ligeira e da produção operística, relacionadas ao antigo modelo monárquico. É preciso levar em consideração que, mesmo em um contexto de estabelecimento do nacionalismo musical enquanto estética prioritária no campo da criação musical, os repertórios canônicos da tradição europeia mantiveram seu caráter de "produto musical distintivo" conservados como força moralizante nas salas de concerto brasileiras.

Em Curitiba, a Scabi pode ser considerada a primeira instituição a direcionar seus esforços na criação de uma estrutura propícia à prática da música de concerto a partir de 1945, por meio da contratação de artistas locais, nacionais e estrangeiros, alinhados a tal posicionamento estético-ideológico. Todo o material produzido pela instituição pode ser entendido como aparato estratégico na disseminação e efetivação do repertório canônico ambicionado pela Scabi e pela intelectualidade local, um modelo musical ideal.

Por meio dos programas de concerto, como se verá, a Scabi utilizou um repertório deliberadamente canônico, ou seja, a produção musical tradicionalizada de compositores do século XVIII e XIX, em especial os mais representativos de cada escola de composição, que configuraria a base educativa no amadurecimento do público, repertório de elevado conteúdo moral. Buscou, do mesmo modo, incutir na plateia local a apreciação de compositores nacionais atuantes à época, buscando, nessa mesma perspectiva, canonizá-los em função da vinculação estética. 
Esse posicionamento foi construído em função de uma produção musical de concerto na cidade que, durante as primeiras décadas do século XX, esteve circunscrita a apresentações esporádicas e isoladas, relativizadas por companhias teatrais e líricas que passavam por Curitiba a caminho de polos maiores, sobretudo Buenos Aires. Assim, parte significativa da música oferecida na cidade transitava entre práticas relacionadas ao amadorismo e ao entretenimento ligeiro, realidade que passou a ser questionada pela intelectualidade local, buscando conferir legitimidade às sociabilidades musicais, uma prática musical que simbolizasse atributos morais e espirituais, determinando o processo de funcionamento da música enquanto disciplina (JUSTUS, 2002).

De acordo com o crítico paranaense Andrade Muricy, importante interlocutor da música nos círculos nacionais, os intelectuais das primeiras décadas do século $X X$ tinham como objetivo a educação artística do povo, pois entendiam que o brasileiro mediano carecia de tradição cultural, uma bagagem de conhecimentos tácitos no campo artístico que contribuiria para a consolidação cultural da sociedade local (MURICY, 1946). Para ele, assim como seus pares, a tradição musical cultural de maior relevância era encontrada na música de concerto europeia e seus repertórios canônicos, amparada no ideário europeu de civilização, que passava também pela sofisticação artística e cultural, do qual a Scabi seria representante no campo da música. Seria impensável nesse contexto, que a chamada elite passasse sua existência sem apreciar um quadro ou ainda uma sinfonia, diria Andrade Muricy, portanto nas décadas de 1930 e 1940 houve intenso trabalho no intuito de direcionar o gosto em formação. Esse direcionamento seria paulatinamente efetivado ao longo do estabelecimento dos novos repertórios canônicos, oportunizados pela atuação das instituições musicais privadas (ANZE, 2009; CARLINI, 2013).

A Scabi pode ser entendida enquanto instituição musical civil fundamentada no ideário da "civilidade", buscando articular tais propostas no campo da música de concerto na cidade de Curitiba, fazendo uso de repertório canônico, visando oferecer um tipo de "alicerce" para a formação artística e cultural da plateia curitibana. Para além da fruição musical, as instituições musicais civis são disseminadoras de repertórios e promovem informação musical a ser assimilada nos seus espaços de sociabilidade, ao mesmo tempo em que contribuem para a legitimação do conteúdo musical que disseminam, a partir do repertório. Nesse sentido, acabam criando condições de acesso e apropriação de obras culturais por meio de concertos promovidos, bem como de outras estratégias que oportunizam a apreciação entre camadas sociais que reconhecem esses bens culturais como elementos de representação e valoração social.

\section{Análise de repertório a partir dos programas de concerto da Scabi: tensões e ideologias}

Ao elencar um determinado contexto musical, a investigação é referenciada tendo como base as "escolas de composição" que caracterizaram um dado momento histórico. De modo geral, no Brasil da primeira metade do século $X X$, optou-se por uma estética musical oriunda de uma tradição canônica. Tal escolha foi associada a um determinado arcabouço de produção musical voltado à construção de uma identidade nacional. 
Esse ideário nacional foi reproduzido no âmbito local em determinados espaços promotores da cultura, como seria o caso das instituições privadas no Paraná.

No Brasil, a noção de nacionalismo enquanto projeto musical foi amplamente disseminada no trabalho de musicólogos como Renato Almeida (1895-1981) na questão nacional traduzida na utilização do folclore como a fonte basilar para escrever e pensar a música, e também no trabalho crítico e musical de Mário de Andrade (1893-1945), que buscou sistematizar e oferecer, por meio das primeiras pesquisas folclóricas, elementos musicais que serviram de fonte para o trabalho dos compositores de música de concerto (ANDRADE, 1972). Dentre os adeptos das propostas nacionalistas figuraram o musicólogo Luiz Heitor Corrêa de Azevedo (1905-
1992) - irmão do presidente da Scabi - e o crítico José de Andrade Muricy (1895-1984); dentre os compositores destacaram-se Heitor Villa-Lobos (1887-1959), Oscar Lorenzo Fernandez (1897-1948), Francisco Mignone (1897-1986), Mozart Camargo Guarnieri (1907-1993), dentre outros, influenciados pela questão nacional como temática de suas respectivas produções, "sem divergências no campo teórico-metodológico ou político" (CONTIER, 1994, p. 39). O alcance dessa estética foi estendido ao Paraná por intermédio da Scabi, no patrocínio a intérpretes que divulgavam em seus repertórios obras de caráter nacionalista, e do mesmo modo pelas estratégias da instituição, que organizou palestras e festivais com a presença dos próprios compositores vinculados ao nacionalismo.

Figura 2: Festival Camargo Guarnieri. $129^{\circ}$ Concerto da Scabi.

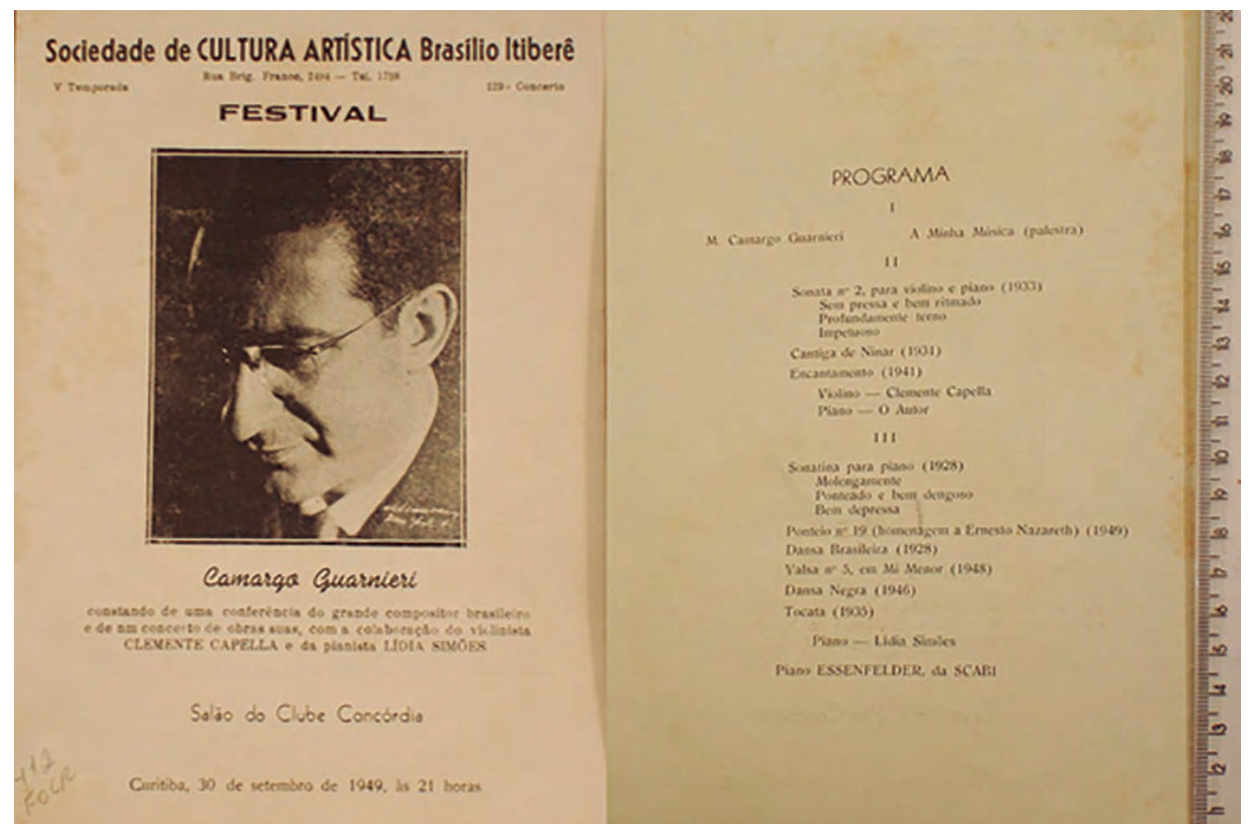

Fonte: Centro de Documentação e Pesquisa da Casa da Memória (Fundação Cultural de Curitiba). Referência de catalogação: 412 FOLR, 1949, Curitiba. Scabi, 30.09.1949 5 . 
Esse posicionamento foi decisivo no que toca à associação ideológica da instituição, sabendo-se que apesar da priorização de uma estética musical nacionalista, o período compreendido entre as décadas de 1940 e 1960 foi marcado por discussões em torno do nacionalismo em oposição à estética de vanguarda, voltada à música experimentalista e universalista, em sintonia direta com questões do mundo contemporâneo ${ }^{6}$. Essa polarização iria compor uma espécie de debate estético que se refletiu no Brasil por meio dos discursos institucionais oficiais, da mídia e do posicionamento da intelectualidade em defesa de um ou outro arcabouço estético. O ambiente social, bem como a conjuntura político-ideológica, em especial no período no pós-guerra, permitiu a discussão sobre novas formas de expressão estética, amplamente disseminadas no país a partir da década de 1960.

Esse debate indica que havia, no cenário nacional, associações específicas a determinado tipo de repertório musical. Nesse ponto, identifica-se a Scabi enquanto instituição cultural contextualizada em período de legitimação da música de concerto canônica, lançando mão de um aparato simbólico concernente à consolidação desse tipo de música no interior do campo artístico. Para tal, serviu-se de instrumental pedagógico no intuito de formar um público capaz de compreender e consumir esse tipo de produto, além de buscar consolidar sua vinculação estética no bojo da produção nacional. Ao fomentar um importante espaço de sociabilidade na capital paranaense, a Scabi centralizou esforços no desenvolvimento de elementos tidos como necessários à construção e à caracterização de um modelo "adequado" de plateia. Para dar corpo a tal projeto, a instituição selecionou um tipo de repertório e desenvolveu parcerias estratégicas com personalidades do meio musical que mantinham posicionamento estético voltado à consolidação e à perpetuação do nacionalismo em música.

Com base na análise dos programas de concerto compreendidos entre os anos de 1945-1963 (um total de 355 recitais), foi possível estabelecer um padrão do repertório disseminado, mais especificamente das correntes de composição executadas pelos intérpretes e adotadas nos concertos pela Scabi. A resultante dessa reflexão entre Scabi, na figura do presidente Fernando Corrêa de Azevedo com seus interlocutores, facilitou a inserção de obras de compositores brasileiros em um momento de amplo debate entre o nacional e o universal.

Para realizar a análise, foi estabelecido diálogo com as obras em seu contexto de vinculação estética e, não necessariamente, com a cronologia dos seus respectivos compositores, relativizando algumas "vanguardas" que eram, na verdade, amplamente aceitas na sociedade brasileira. Ao se analisar a obra do compositor francês Claude Debussy (1862-1918), apesar de identificar importantes pontos de redefinição dos paradigmas da estruturação harmônica, da forma e do plano textural em música, percebe-se que a natureza e as consequências de sua revolução estética só seriam "plenamente reconhecidas após a Segunda Guerra" (GRIFFITHS, 2011, p. 13), na Europa.

A tabela 1 indica o modelo adotado para quantificar, anualmente, os dados referentes ao repertório executado. O procedimento foi repetido ao longo dos anos subsequentes até 1963, procurando-se dar ênfase à recorrência do repertório na seção referente aos compositores, atentando para a formação instrumental de cada concerto realizado. 
Tabela 1: Exemplo de categorização dos concertos da SCABI entre os anos de 1945-1947

\begin{tabular}{l|c}
\hline \multicolumn{2}{c}{1945} \\
\hline Compositores Sec. XVI & 0 \\
Compositores Sec. XVII & 5 \\
Compositores Sec. XVIII & 7 \\
Compositores Sec. XIX & 60 \\
Nacionalismo brasileiro & 48 \\
Compositores de & 3 \\
vanguarda & 8 \\
Canto & 0 \\
Conjunto câmara & 2 \\
duos & 0 \\
coro & 7 \\
piano & 0 \\
violão & 0 \\
Orquestra & $\mathbf{8 9}$ \\
Peças curtas & $\mathbf{2}$ \\
Peças maiores (3 ou \\
mais mov.)
\end{tabular}

\begin{tabular}{l|c}
\hline \multicolumn{2}{c}{1946} \\
\hline Compositores Sec. XVI & 0 \\
Compositores Sec. XVII & 14 \\
Compositores Sec. XVIII & 10 \\
Compositores Sec. XIX & 49 \\
Nacionalismo brasileiro & 26 \\
Compositores de & 0 \\
vanguarda & 2 \\
Canto & 1 \\
Conjunto câmara & 3 \\
duos & 0 \\
coro & 3 \\
piano & 0 \\
violão & 2 \\
Orquestra & $\mathbf{9 1}$ \\
Peças curtas & $\mathbf{1 0}$ \\
Peças maiores (3 ou \\
mais mov.)
\end{tabular}

\begin{tabular}{l|c}
\hline \multicolumn{2}{c}{1947} \\
\hline Compositores Sec. XVI & 2 \\
Compositores Sec. XVII & 20 \\
Compositores Sec. XVIII & 22 \\
Compositores Sec. XIX & 66 \\
Nacionalismo brasileiro & 47 \\
Compositores de & 6 \\
vanguarda & 1 \\
Canto & 1 \\
Conjunto câmara & 3 \\
duos & 1 \\
coro & 15 \\
piano & 0 \\
violão & 8 \\
Orquestra & $\mathbf{1 2 6}$ \\
Peças curtas & $\mathbf{3 6}$ \\
Peças maiores (3 ou \\
mais mov.)
\end{tabular}

Dentre os compositores destacados, Beethoven aparece como o compositor proeminente, com um total de 113 obras apresentadas, em sua grande maioria, sonatas para piano e sinfonias executadas pela orquestra sinfônica da Scabi. A partir de Beethoven, outros compositores completam a lista dos mais executados em concertos: Johann Sebastian Bach (século XVII) com 98 obras, seguido de Mozart (século XVIII) com 90. Aqui, tem-se três dos compositores mais emblemáticos desse movimento canônico da música de concerto, confirmando a expectativa de que em Curitiba o processo de estabelecimento de um repertório partiria daquele legitimador, presente nas personagens consagradas da tradição musical suas maiores representantes. A partir dessa tríade, o século XIX desponta como a proposta musical mais oferecida pela Scabi: Chopin foi executado 82, Debussy 75, Brahms 51 e Schumann 46 vezes.
Essa característica é justificável, uma vez que para a Scabi, os recitais de piano possibilitariam maior trânsito de instrumentistas na cidade e uma maior variedade de eventos promovidos pela instituição. Ao todo, contabilizou-se 106 recitais de piano, sem levar em conta eventos em que o piano figurou como instrumento de correpetição. Como instrumento preponderante na produção musical dos séculos XVIII e XIX, é possível compreender a predominância de compositores que dedicaram parte de sua produção ao repertório pianístico.

A partir do levantamento quantitativo do número de execuções de obras dos compositores e suas respectivas vinculações estéticas ao longo de cada temporada artística da Scabi até 1963, é possível confirmar uma prática de repertório enraizada na tradição musical do século XIX, com 675 obras executadas. Entretanto, os primeiros seis anos de atuação da Scabi em Curitiba, entre 1945- 
1950 demonstram a existência recorrente de obras de compositores engajados no movimento nacionalista. Com base nas referências dos musicólogos brasileiros atuantes àquele período - em especial Azevedo (1956), irmão do presidente da Scabi - e na categorização por eles realizadas quanto aos compositores que adotaram o nacionalismo em suas propostas, estabeleceu-se um total de 223 obras executadas. Comparativamen- te aos demais repertórios disseminados, a música de concerto nacionalista teve praticamente o dobro de execuções ao longo das 19 temporadas artísticas analisadas, 412 obras, em comparação ao repertório do século XVII, que contou com 219 ocorrências, e 246 do século XVIII. A tabela 2 demonstra essa realidade, após levantamento total dos eventos entre 1945-1963.

Tabela 2: Categorização final das escolas de composição executadas em concertos da Scabi entre os anos de 1945-1963.

\begin{tabular}{l|c}
\hline \multicolumn{2}{c}{ TOTAL (1945-1950) } \\
\hline Compositores Sec. XVI & 6 \\
Compositores Sec. XVII & 88 \\
Compositores Sec. XVIII & 92 \\
Compositores Sec. XIX & \\
Nacionalismo brasileiro & \\
Compositores de vanguarda & 18 \\
\hline
\end{tabular}

\begin{tabular}{l|l}
\hline \multicolumn{2}{c}{ TOTAL (1951-1960) } \\
\hline Compositores Sec. XVI & 16 \\
Compositores Sec. XVII & \\
Compositores Sec. XVIII & \\
Compositores Sec. XIX & \\
Nacionalismo brasileiro & \\
Compositores de vanguarda & 27 \\
\hline
\end{tabular}

\begin{tabular}{l|c}
\hline \multicolumn{2}{c}{ TOTAL (1961-1963) } \\
\hline Compositores Sec. XVI & 6 \\
Compositores Sec. XVII & 14 \\
Compositores Sec. XVIII & 37 \\
Compositores Sec. XIX & 61 \\
Nacionalismo brasileiro & 35 \\
Compositores de vanguarda & 5 \\
\hline
\end{tabular}

Não se pretende aqui afirmar que a produção dos compositores nacionalistas foi a mais importante dentre os repertórios trazidos a Curitiba, mas os dados indicam claramente que, no momento em que havia amplo debate estético sobre novas formas de ruptura com a produção musical estabelecida, na capital paranaense se fazia uso de repertórios tradicionalizados e amplamente aceitos, dentre os quais os do nacionalismo brasileiro que se consolidava. É inegável o fato de a instituição ter contado com o apoio de interlocutores que defendiam uma produção musical nacional, representantes do projeto estético nacionalista em música. $\mathrm{O}$ repertório tem papel fundamental no estabelecimento do cânone musical, uma vez que a execução isolada de obras não as estabelece como parte do cânone, a cultura musical precisa confirmar tal autoridade e chancelá-la de maneira sistemática, ao menos em algum grau (WEBER, 1999, p. 537).

Interlocutor da Scabi, o crítico Andrade Muricy negava de maneira enfática práticas musicais que levassem em consideração o conceito de universalismo, criticando a adoção de esquemas alheios e externos ao processo composicional, fazendo alusão ao dodecafonismo defendido pelo grupo Música Viva, uma prática "fora da realidade histórica brasileira". Por fim, acreditava que o modelo era inverso: devia partir do nacional aos processos internacionalizados de composição, sendo "necessário, agora, que tratemos de libertar a alma do nosso país, e que misturemos essa cor local à alma internacional" (CONTIER, 1991, p. 13-14). Assim como Muricy, Luiz Heitor Corrêa de Azeve- 
do foi importante articulador musical junto à Scabi, no sentido de possibilitar o trânsito de músicos e compositores nacionais e estrangeiros. Ambos defendiam o ideal nacionalista preconizado por Mário de Andrade e representado pelos compositores incorporados nos programas de concerto da Scabi.
Muricy e Luiz Heitor transitaram pelo Paraná e contribuíram, direta ou indiretamente, na divulgação da Scabi para a circulação de músicos para configuração do seu repertório, que inegavelmente partilhava e disseminava o mesmo ideário no âmbito local.

Figura 3: Primeiro centenário de nascimento de Henrique Oswald. 197 e $198^{\circ}$ Concerto da Scabi

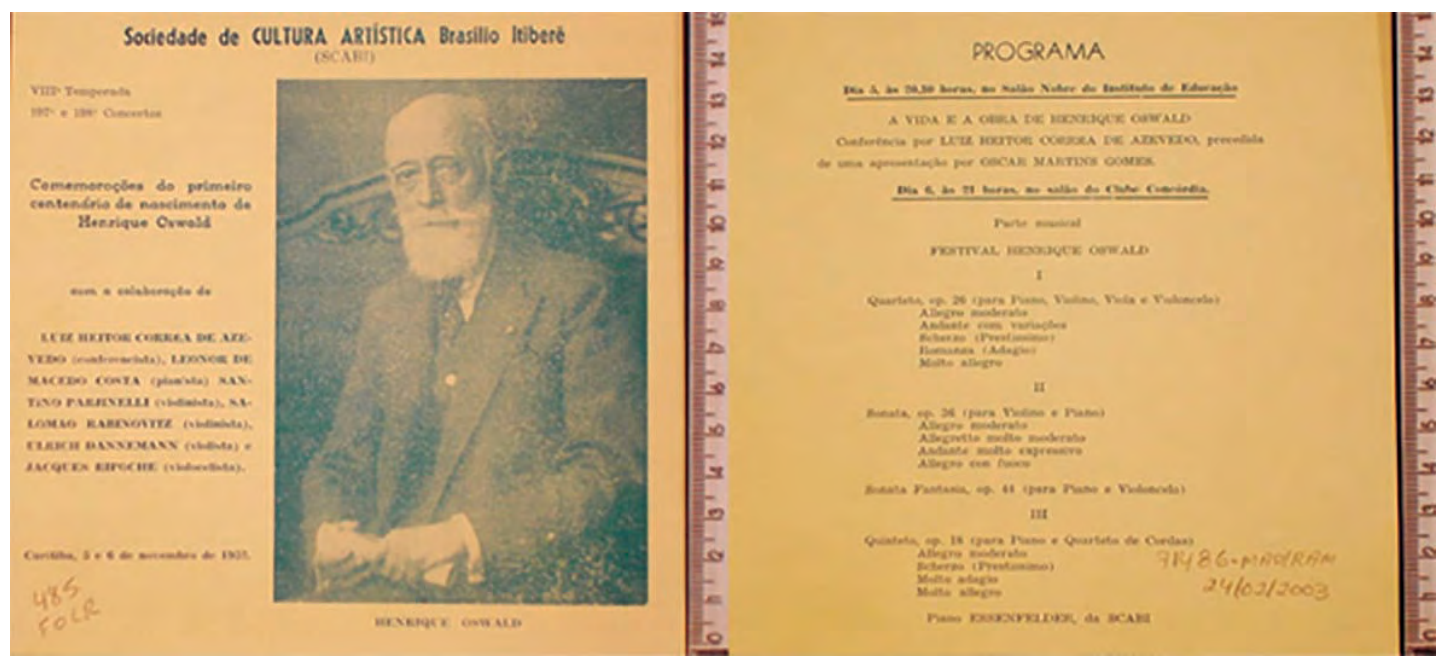

Fonte: Centro de Documentação e Pesquisa da Casa da Memória (Fundação Cultural de Curitiba). Referência de catalogação: 485 FOLR, 1952, Curitiba. SCABI, 05 e 06.11.1952 ${ }^{7}$.

Dentre os nomes mais proeminentes da produção musical nacionalista nas fontes analisadas, destacaram-se execuções de obras de Villa-Lobos (77 obras - o quinto compositor mais executado pela Scabi), Lorenzo Fernandez (21 obras), Camargo Guarnieri (34 obras) e Francisco Mignone (40 obras). Alguns desses compositores, inclusive, atuaram presencialmente em Curitiba, ministrando conferências sob o patrocínio da Scabi com temáticas relacionadas à nacionalização e à identidade de uma música genuinamente brasileira. Em artigo de periódico local, a Gazeta do Povo anunciou em marco de 1947: “Lorenzo Fernandez dissertará sobre a nossa música que é a sua música e da qual é um dos mais idôneos representantes" ${ }^{\prime \prime}$. Em setembro de 1949, o periódico O Dia indicaria que "Camargo Guarnieri teve como orientador da sua formação estética e musical o grande Mário de Andrade [...].é sem dúvida, juntamente com Villa Lobos, uma das maiores expressões da música brasileira" ${ }^{9}$. 


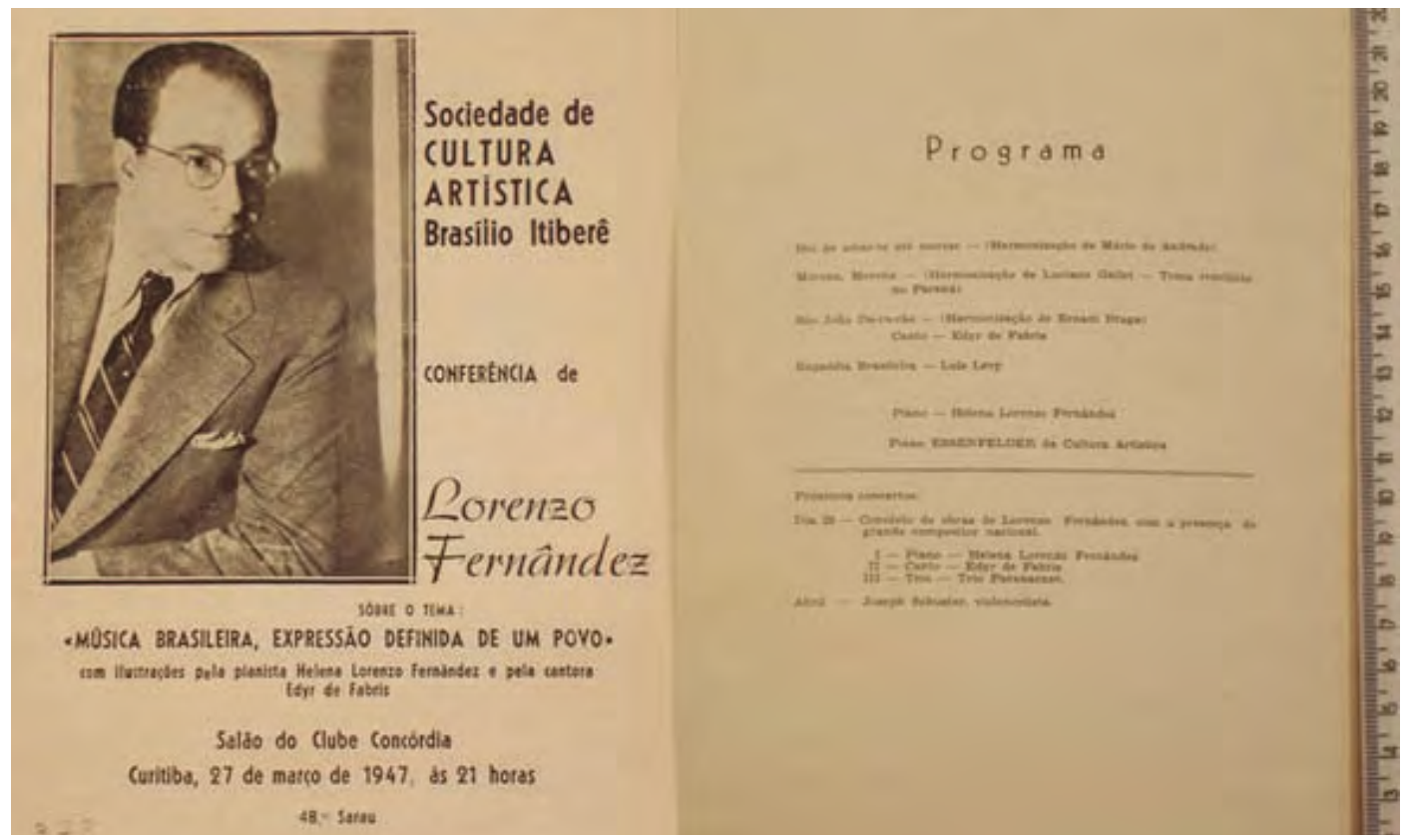

Fonte: Centro de Documentação e Pesquisa da Casa da Memória (Fundação Cultural de Curitiba). Referência de catalogação: 378 FOLR, 1947, Curitiba. Scabi, 27.03.1947 ${ }^{10}$.

É preciso levar em conta que o círculo de intérpretes também era influenciado pelas opções estéticas em vigência, nesse período havia intensa atividade dos compositores brasileiros que intermediavam suas obras para execuções públicas, transitavam em várias instâncias educativas e formavam musicistas para a promoção de música nacionalista, nos conservatórios e nas academias de música oficiais que se estabeleciam. Arnaldo Rebello, por exemplo, pianista que realizaria concertos em Curitiba patrocinados pela Scabi, recebia obras dos compositores por ser entendido como um "exímio musicista nacional, reconhecido como um dos intérpretes mais abalizados em relação à música brasileira [...] Para ele têm escrito especialmente alguns dos maiores compositores"11.
Estratégia estabelecida pela Scabi, visando oficializar este circuito de produção musical de caráter nacional, foi empreendida na série de concertos "Festival de Música Brasileira". Na análise dos programas de concerto e relatórios anuais da Scabi, é possível identificar que essa realização ocorreu desde o ano de 1947, período que marca o momento de grande repercussão no debate estético entre o nacionalismo e a produção de vanguarda impulsionada pelo grupo $M u ́$ sica Viva. Lista-se abaixo a relação de festivais vinculados à produção de repertório de concerto nacionalista.

Festivais: 1947 - Lorenzo Fernandes; 1948-Panorama da Música Brasileira; 1949Camargo Guarnieri; 1950 - Alceu Bocchino; 1952-Henrique Oswald; 1953-Lorenzo 
Fernandes 1954 - Seria realizado um Festival Villa-Lobos e/ou Francisco Mignone, entretanto a SCABI indicou dificuldades nos entendimentos com os compositores; 1956 - Itiberês (Brasilio Itiberê, João Itiberê da Cunha e Brasílio Itibere da Cunha Luz); 1960 - Música brasileira; 1962 - Ciclo evolutivo da música brasileira de piano, um conjunto de três concertos, ilustrando o panorama "evolutivo" da música dos compositores brasileiros, iniciando na famosa "A Sertaneja" de Brasílio Itiberêê ${ }^{12} ; 1963$ - Francisco Mignone. 1951/57/59/61 - não foram realizados festivais.

Os Festivais de Música Brasileira da Scabi objetivavam demarcar, simbolicamente, o repertório de música nacional no espaço artístico curitibano, especificado em evento exclusivo. Como os repertórios convencionais dos intérpretes eram variáveis, e podiam ou não contar com a inclusão de obras de nacionalistas, estes festivais conseguiam captar em essência a proposta de peças musicais de compositores associados ao espírito nacional.

Para a concretude do projeto aceitação e inclusão do repertório em um dado contexto, a execução musical por si só não estabelece sua integração ao cânone, é preciso que a cultura musical assegure sua autoridade, estabelecida por uma crítica musical e pelo desenvolvimento de ferramentas que garantam sua cidadania (WEBER, 1999, p. 349). Acredita-se que o trabalho da Scabi tenha sido orientado nessa perspectiva, oportunizar o incremento da cultura musical em Curitiba, criando estratégias de efetivação pedagógica do cânone relacionado à música de caráter nacionalista - Festivais de Música Brasileira, palestras com os compositores e musicólogos vinculados ao movimento - elementos imprescindíveis para a disseminação da produção musical nacional, à época pouco conhecida na cidade. Desse modo, é possível afirmar que a Scabi se posicionou ideologicamente ao optar pela permanência e ampliação dos repertórios vinculados à estética nacionalista, e ao incorporar o discurso e se vincular ao movimento engajado de uma escola nacional de composição, a instituição fomentou um tipo específico de repertório no intuito de estabelecê-lo e justificá-lo, para além da tradição romântica dos repertórios dos séculos XVIII e XIX.

\section{Considerações finais}

Procurou-se demonstrar que a Scabi teve como premissa o estabelecimento de uma prática musical voltada à música de concerto na cidade de Curitiba, por meio da realização de eventos musicais vinculados à disseminação de repertório canônico. Do mesmo modo, a entidade ampliou suas propostas de atuação por meio dos contatos estabelecidos com personalidades artísticas que circularam em seus espaços, todos representantes de uma estética nacionalista em música. A relevância dos programas de concerto em quanto fontes para a análise das opções estéticas de uma dada instituição, oportunizou um novo olhar sobre entidades civis promotoras de eventos musicais. Essa tipologia de fonte enfatizou as opções estéticas da Scabi por meio dos concertos disseminados, priorizando o nacionalismo nesse 
bojo de discussões entre esta estética e a vanguarda que procurava se estabelecer.

A partir das questões levantadas, tendo como base a análise dos programas de concerto da instituição, afirma-se que as diferentes frentes de atuação da Scabi buscaram contribuir para a ampliação de sua atuação na cidade, e do mesmo modo, para a definição de uma proposta musical calcada na ampliação do repertório vinculado ao movimento de disseminação da estética nacionalista. Apesar da carga ideológica da tradição musical canônica, a produção da Scabi aponta para a incorporação desse modelo estético nacionalista como tentativa, inclusive, de superação do modelo tradicionalizante europeu, amplamente questionado no Brasil do período, quer pelos nacionalistas, quer pelos vanguardistas.

Em confirmação à realidade apresentada pela análise dos programas de concerto da Scabi, pesquisas semelhantes (MARIN, 2013) corroboram a ideia sobre a programação na música de concerto ser caracterizada pela concentração em grande quantidade de uma estética baseada no repertório clássico romântico com incursões pontuais nas primeiras vanguardas. Em Curitiba, este cenário se faz presente, com a adesão das especificidades inerentes ao contexto cultural vivenciado nesse período, relacionadas à inclusão e à disseminação constante de repertório de compositores brasileiros de cunho nacionalista, em um momento de franco debate entre correntes estéticas no Brasil.

O cânone indica, em última instância, a maneira que, por meio da história, se cristalizam valores que o identificam à cultura do grupo que representa, constituindo um imaginário de coesão e identidade, um lugar no qual se articulam individualidade e consenso coletivo. Ao tentar ampliar a tradição de repertório constituído, a Scabi procurou estabelecer um novo modelo a ser assimilado, aceito e perpetuado na sociedade local. Sua atividade, apesar de não excluir o repertório da tradição musical europeia, tencionou incluir a estética musical nacionalista, com vias de conferir autenticidade a esse repertório na cidade, participando, assim, do debate que cercava o período, em especial nos últimos anos da década de 1940, sobre o nacionalismo como fonte para a produção de música de concerto.

\section{Abstract}

The present article carried out an investigation based on concert programs as a primary source, analyzing the aesthetic position of the Sociedade de Cultura Artística Brasílio Itiberê (SCABI) through the repertoire disseminated in Curitiba-PR. From the quantitative survey of works by the composers and their respective aesthetic bonding throughout each artistic season of SCABI (19451963), it is possible to confirm a repertoire practice rooted in 19th century musical tradition with incursions into nationalist production. This action reveals a movement in the sense of opportunizing the internalization of a type of institutionalized repertoire, justifying nationalism without breaking with the canonical repertoire of the European tradition, at a clear moment of tension in the concert music field between the Nationalism $\mathrm{x}$ universalism.

Keywords: Concert programs. Canonical repertoire. Musical nationalism. 


\section{Resumen}

El presente artículo realizó una investigación basada en programas de concierto como fuente primaria, analizando el posicionamiento estético de la institución de promoción musical Sociedade de Cultura Artística Brasílio Itiberê (SCABI) por medio del repertorio diseminado en Curitiba-PR. A partir del levantamiento cuantitativo de obras de los compositores y sus respectivas vinculaciones estéticas a lo largo de cada temporada artística de la SCABI (1945-1963), es posible confirmar una práctica de repertorio arraigada en la tradición musical del siglo XIX con incursiones en la producción nacionalista. Se cree que tal actuación revela un movimiento en el sentido de oportunizar la internalización de un tipo de repertorio institucionalizado, justificando el nacionalismo sin romper con el repertorio canónico de la tradición europea, en un momento nítido de tensiones en el campo de la música de concierto Nacionalismo $\mathrm{x}$ universalismo.

Palabras clave: Nacionalismo musical. Programas de concierto. Repertorio canónico.

\section{Notas}

O recorte é justificado pela indisponibilidade referente à documentação da Scabi a partir de 1964, em especial àquela relacionada aos programas de concerto. Optou-se portanto pela análise das fontes compreendidas entre 1945 e 1963 pois estão preservadas sequencialmente na Casa da Memória, Fundação Cultural de Curitiba.
2 Festival de Música brasileira. $314^{\circ}$ Concerto da Scabi. Centro de Documentação e Pesquisa da Casa da Memória (Fundação Cultural de Curitiba). Referência de catalogação: 634 FOLR, 1960, Curitiba. Scabi, 28.10.1960.

3 LANGE, Francisco Curt. [Correspondência] 07. jul.1946, Montevidéu. Acervo Curt Lange. Biblioteca da Universidade Federal de Minas Gerais.

4 AZEVEDO, Fernando Corrêa. [Correspondência] 28. jul.1946, Curitiba. Acervo Curt Lange. Biblioteca da Universidade Federal de Minas Gerais.

5 Festival Camargo Guarnieri. $129^{\circ}$ Concerto da Scabi. Centro de Documentação e Pesquisa da Casa da Memória (Fundação Cultural de Curitiba). Referência de catalogação: 412 FOLR, 1949, Curitiba. Scabi, 30.09.1949.

6 Um movimento contemporâneo ao nacionalismo da década de 1940 ficou conhecido como Música Viva, concebido com enfoque de caráter educativo (formação), de criação (composição) e divulgação (interpretação, apresentações públicas, edições, transmissões radiofônicas), voltado à movimentação de ideias e atualização do ambiente musical em relação às novas tendências. $O$ veio vanguardista do grupo seria ampliado por meio de composições e palestras, delimitando nesse processo seu campo estético, vinculado prioritariamente ao dodecafonismo da Segunda Escola de Viena (KATER, 2006).

7 Conferência de Lorenzo Fernandez. $48^{\circ}$ Concerto da SCABI. Centro de Documentação e Pesquisa da Casa da Memória (Fundação Cultural de Curitiba). Referência de catalogação: 378 FOLR, 1947, Curitiba. Scabi, 27.03.1947.

8 Periódico GAZETA DO POVO, Curitiba, 27 de março de 1947. HSCabi - I70. Pasta Scabi. Hemeroteca, Centro de Documentação e Pesquisa da Casa da Memória, FCC.

9 Periódico O DIA, Curitiba, 30 de setembro de 1949. HSCabi - II109. Pasta SCABI. Hemeroteca, Centro de Documentação e Pesquisa da Casa da Memória, FCC.

10 Conferência de Lorenzo Fernandez. $48^{\circ}$ Concerto da Scabi. Centro de Documentação e Pesquisa da Casa da Memória (Fundação Cultural de Curitiba). Referência de catalogação: 378 FOLR, 1947, Curitiba. Scabi, 27.03.1947.

11 Programa de Concerto Festival de música brasileira. $314^{\circ}$ Concerto da SCABI. 634 FOLR, 1960. Curitiba. Scabi, 28.10.1960.

12 Programa de Concerto Festival Ciclo evolutivo da música brasileira de piano. $326^{\circ}, 327^{\circ}$ e $328^{\circ}$ Concerto da SCABI. 656 FOLR, 1962. Curitiba. Scabi, 27 a 29.03.1962. 


\section{Referências}

ANDRADE, Mário. Ensaio sobre a música brasileira. 3. ed. São Paulo: Martins Ed.,1972.

ANZE, Melissa. Sociedade Pró-Música de Curitiba (SPMC): Análise histórico-social da música erudita na capital paranaense (1963-1988). 2010. 149 f. Dissertação (Mestrado em Música), Universidade Federal do Paraná, Curitiba, 2010.

BLANNING, Tim. O triunfo da música: a ascensão dos compositores, dos músicos e de sua arte. São Paulo: Companhia das Letras, 2011.

BURKE, Peter (Org.). A escrita da história: novas perspectivas. São Paulo: Unesp, 1992.

CAMPOS, Luís Melo. A música e os músicos como problema sociológico. Revista Crítica de Ciências Sociais. França, 78, Out. 2007 p. 71-94.

CARLINI, Álvaro Luiz Ribeiro da Silva. Aspectos culturais e artísticos de Curitiba na última década do século XIX: a1) Grêmio Musical Carlos Gomes (1893-1902). In: Simpósio de Pesquisa em Música, 6, 2013, Curitiba. Anais... Curitiba: UFPR. Departamento de Artes, 2013, p. 124-132.

CONTIER, Arnaldo Daraya. Mário de Andrade e a Música Brasileira. In: Revista Música, São Paulo, v. 5, n. 1, maio, 1994. p. 33-47.

. Memória, história e poder: A sacralização do nacional e do popular na música (1920-50). In: Revista Música, no 1, v. 2, São Paulo, maio, 1991, p. 5-36.

. Brasil Novo: música, nação e modernidade. Os anos 20 e 30. Tese de livre docência. FFLCH $\square$ USP , 1988.

GRIFFITHS, Paul. Música moderna. Rio de Janeiro, Zahar, 2011.
JUSTUS, Liana Marisa. Práticas, plateias e sociabilidades musicais em Curitiba nas primeiras três décadas do século XX. 2002. 239f. Dissertação (Mestrado em História), Universidade Federal do Paraná, Curitiba, 2002.

KATER, Carlos. Música Viva. Revista Textos do Brasil Ministério das Relações Exteriores, v.12, 2006, p.89-95.

LE GOFF, Jacques. Documento/monumento. In: História e memória. 4. ed. Campinas: Unicamp, 1996, p. 538-554.

MARIN, Miguel. Tendencias y desafíos de la programación musical. In: Brocar: Cuadernos de Investigación Histórica, v. 37, 2013, p. 87-104.

MURICY, Andrade. Caminho de Música. Curitiba: Guaíra, 1946.

SENNETT, Richard. O declínio do homem público: as tiranias da intimidade. São Paulo: Ed. Companhia das Letras, 1989.

WEBER, William. La gran Transformación en el gusto musical: la programación de conciertos de Haydn a Brahms. Buenos Aires: Fondo de Cultura Económica, 2011.

. The History of Musical Canon. In: COOK, Nicholas; EVERIST, Mark. Rethinking Music. Oxford: Oxford University Press, 1999, p. 336-355. 